\title{
Implementation of a Preventive Maintenance System Based on Augmented Reality
}

\author{
Rabie Hamidane ${ }^{1}$, Leila Hayet MOUSS ${ }^{2}$, Abdelkader Bellarbi ${ }^{3}$, Rafik MAHDAOUI ${ }^{4}$ \\ ${ }^{1,2,4}$ Laboratoire Automatique et Productique (LAP) Université de Hadj Lakhdar \\ Batna, Algeria \\ ${ }^{3}$ Centre de Développement des Technologies Avancées (CDTA) \\ Algiers, Algeria \\ 1'hamidane.rabie@gmail.com, ${ }^{2}$ hayet_mouss@yahoo.fr, ${ }^{3}$ abellarbi@cdta.dz, ${ }^{4}$ Mehdaoui.rafik@yahoo.fr
}

\begin{abstract}
In this article, we present ARPM (Augmented Reality-based Preventive Maintenance) system, which aims at offering to the technician of a Cement Factory a virtual assistance in real time using various forms of 3D models, images or even texts, in order to help him to maintain and inspect his equipment. This system not only offers the possibility of reducing costs of the preventive maintenance, but also allows monitoring and even anticipating failures.

In order to ensure a reliable maintenance operation, we adapted our system to be compatible with the CMMS system (Computerized Maintenance Management System) already exists in the Cement factory.
\end{abstract}

Keywords: Augmented Reality; CMMS; Preventive maintenance; Smartphone; AR glasses.

\section{INTRODUCTION}

The emergence of ICT and the strong expectation of the industrial world to integrate new tools of technological assistance through augmented reality and their integration in the field of maintenance of industrial systems, which is a major concern for business, has become crucial. In order to cope with the need of the market and economic competition.

In this highly competitive global context, the integration of new technologies has become unavoidable, in order to ensure the efficiency of maintenance tasks. Indeed, when an operator working alone or a beginner needs help, it is not necessarily easy to find the person around the world with the level of skill and knowledge that can assist. With the RA, we can now consider a maintenance system allowing the technician to see in real time and in augmented reality which equipment requires a preventive maintenance operation the steps to follow and the material and human resources for this operation.

Hence, our proposed system should have the following objectives:

- Provide modern inspection with augmented reality.

- Minimize the intervention and maintenance costs.

- Avoid system's failures.

\section{STATE OF THE ART}

\section{A. INDUSTRIAL MAINTENANCE}

The main goal of each company or industry is to ensure the triplet "cost, quality and time", it is not the easiest that appears, but one of the essential solutions is maintenance.
However, maintenance has long been considered as an inevitable harm for its importance and because of the high cost

In many industrial fields, especially for production companies, this inevitable harm is always present, but it is not a bad thing for the experts or the maintenance engineers considering the very high costs in the realization of any type of maintenance.

To ensure very good preventive maintenance, this requires the use of computer tools, in other words, the Computer-Aided Maintenance Management (CAMM); and other tools using expert systems and augmented reality techniques, etc.

\section{B. MAINTENANCE}

'Maintenance' means all the corresponding technical and administrative actions, including monitoring and control operations, intended to maintain (preventative maintenance) or restore (corrective maintenance) an entity in a specified state or under conditions Dependability data, (Availability, Reliability, Maintainability and Security) enabling it to perform a required function. [1].

\section{a. TYPES OF MAINTENANCE}

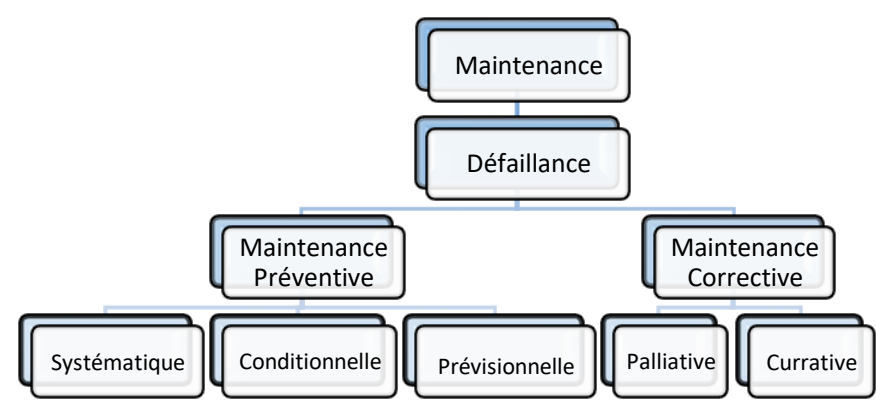

Fig. 1 Diagram of different maintenance concepts [3]

According to Fig. 1, there are two main types of maintenance: preventive and corrective, and each type are divided in turn into other types.

In our work, we are interested in preventive maintenance.

\section{b. PREVENTIVE MAINTENANCE}

A maintenance operation is performed prior to the detection of a failure of an entity, at predetermined date or according to prescribed parameters (following the analysis of the monitored evolution of the significant parameters) is 
intended to reduce the probability of dysfunction of an entity or their degradation [3].

If an entity fails before a maintenance date occurs, it is not repaired and will wait for the next preventive maintenance date.

Preventive intervention is used to improve the state of the element. Therefore, only progressive failures are taken into account here. A preventive maintenance policy aims to:

- Reduce the costs of failure;

- Increase the reliability of a machine;

- Improve the availability of the production workshop;

- Increase the effective life of a machine;

- Improve the scheduling of works;

- Facilitate inventory management

- Ensure security, etc.

There are several types of preventive maintenance, namely: systematic, conditional, critical, cyclic, indicative, limited and regular.

In order to facilitate the preventive maintenance operation, several systems are used in the industrial processes such as programmable logic controllers and microcomputers, the CMMS that offers an information system for maintenance management, namely preventive maintenance. To ensure very reliable maintenance without the assistance of experienced technicians, the use of augmented reality techniques is suggested as an effective solution.

\section{C.AUGMENTED REALITY FOR MAINTENANCE}

In 1992 by Tom Caudell and David Mizell was used for the first time the term augmented reality [4] to name the superposition of computerized material on the real world. Their project aimed to help technicians in aircraft to maintain their equipment.

In recent years, several research projects have been carried out on industrial maintenance using AR.

AR has entered in the life cycle of industrial products through the ARVIKA system [5], the problem of maintenance tasks on complex mechanical equipment is solved by the STARMATE system [6]. In 2006 the ULTRA system helps mobile maintenance technicians to carry out maintenance tasks using augmented reality [7]. (BMW) uses augmented reality for automotive maintenance [8]. The ARMAR system [9] proves that RA gives very high productivity, accuracy and safety.

Didier [10] proposed a guided maintenance system using mobile augmented reality. This system is designed to illustrate a maintenance plan for equipment using mobile augmented reality. The shortcomings observed in this system; lie in that this system is focused on guided collaborative remote maintenance and not for preventive maintenance.

In 2010, Bottecchia et al. proposed TAC System: collaborative tele-assistance [11], whose objective is to ensure a supervised collaborative industrial maintenance task

ZENATI presented a research paper that deals with a new software architecture model, the PAC-Amodeus model for the design of an augmented reality system [12]. This research focuses on the software engineering component of AR systems.

In [13], a real-time remote collaboration system using mobile augmented reality based on the use of hand gestures is presented. To help the remote technician perform manual tasks.

In [14], an industrial equipment maintenance training system is proposed. In 2013, Benbelkacem [15] proposed an improvement for this system, after that ZENATI [16] proposed other improvement that integrates e-maintenance in the system.

(Curative maintenance) The concept of preventive maintenance does not exist in these works. Our objective is to realize a preventive maintenance system using augmented reality to illustrate the equipment that requires a maintenance operation in a workshop inspection using the remaining duration of the operation and the tools and human resources required for the maintenance operation.

In our work, we have chosen the filtration workshop as a field of application in the cement factory of Elma-Labiod Tébessa "Société des Ciment de tébessa" (SCT).

\section{PROPOSED SYSTEM}

\section{A. PRESENTATION OF (SCT)}

The cement company of Elma-Labiod Tébessa is a subsidiary of the group GICA (group industriel des ciments de l'algerie), since 1994 it is installed in Algeria by the FLS Denmark manufacturer. The factory has a nominal production capacity of six hundred thousand tons per year on a single production line. Supervision of this production system is ensured by the FLS Expert Control Supervision (ECS) system. Fig. 2 shows the process of making cement. 


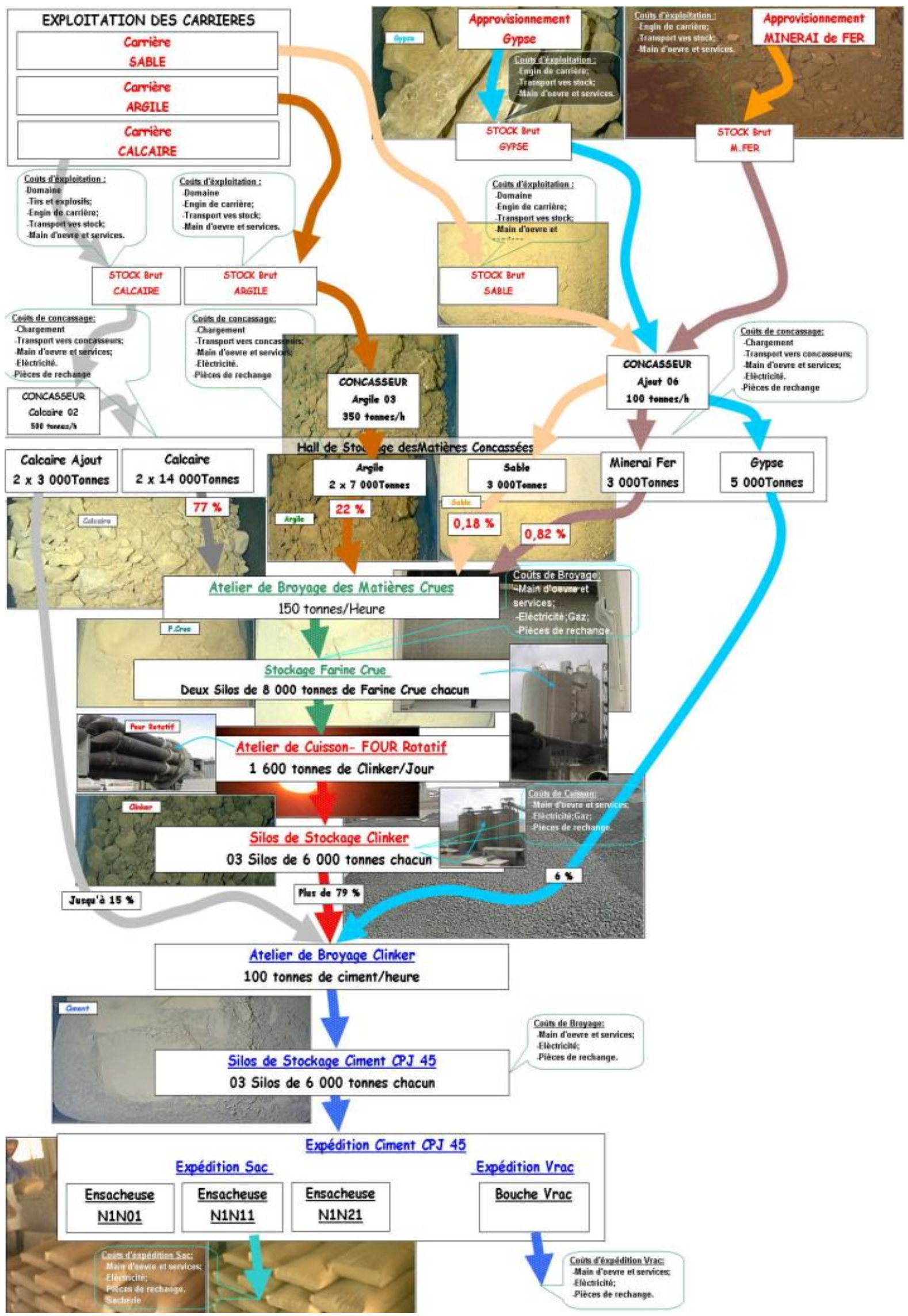

Fig. 2 Cement manufacturing process [2]. 


\section{B. A.R.P.M System}

During an inspection of the works in the Elma-labiod cement plant, the technician may use anti-reflective glasses or a Smartphone and through our system (A.R.P.M) to identify the equipment requiring a preventive maintenance operation, as well as the remaining time for this operation, as well as for the necessary tools and personnel.

Figure 3 shows a platform for communication between our system and the CMMS database server using mobile devices. As well as Figure 4 represents the frame of the system.

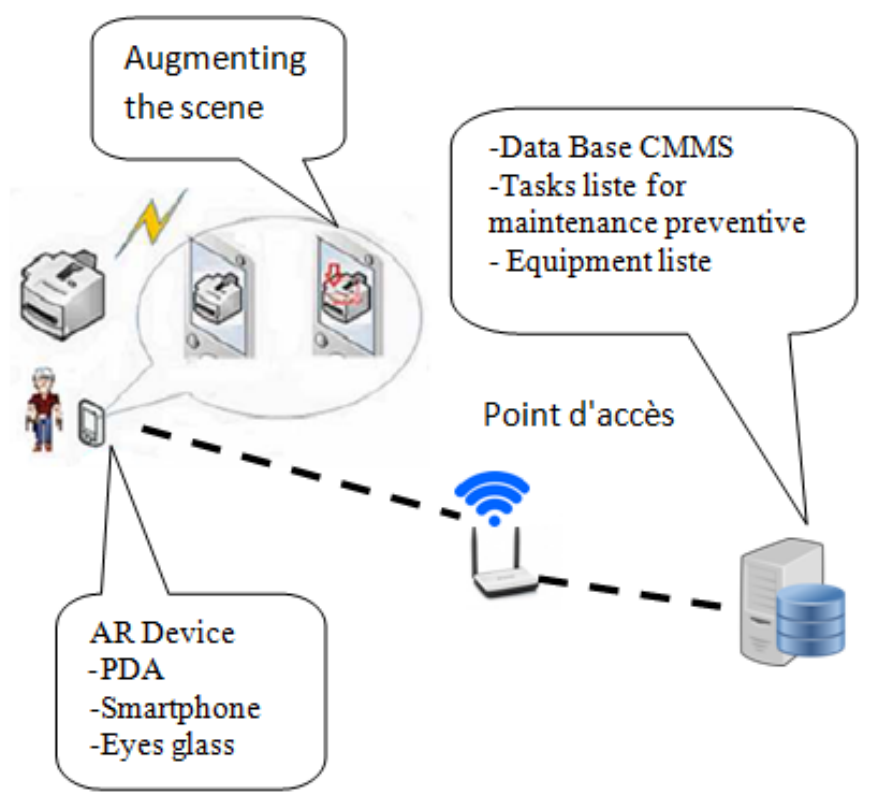

Fig. 3 A.R.P.M platform configuration.

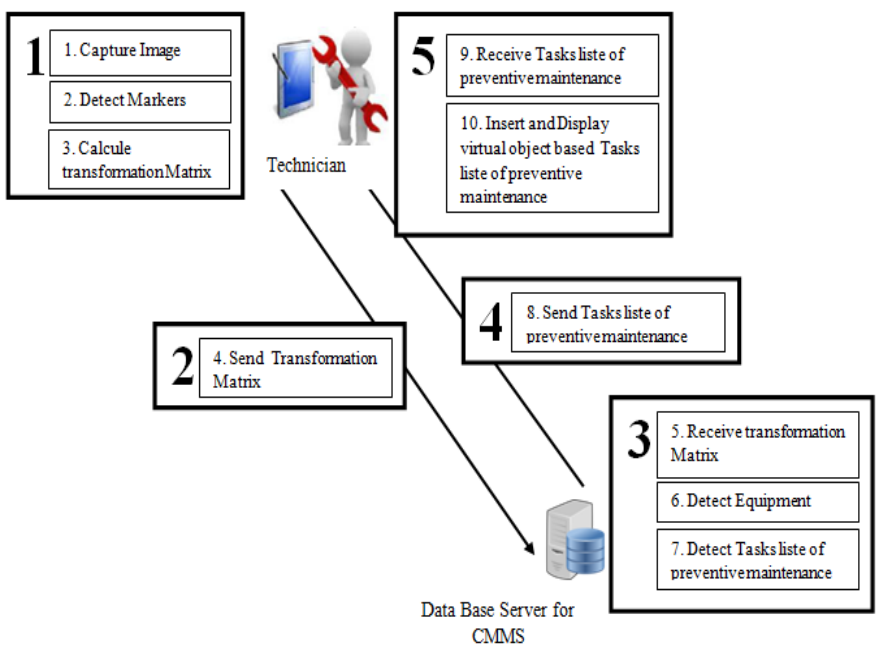

Fig. 4 Framework of the system

\section{IMPLEMENTATION AND RESULTS}

We used ARToolkit, Unity 3D and C \# programming to implement our system. In this section we have presented an android version of our system. We tested our system on the draft fan of the Tébessa cement plant. Using Smartphone which has an Android operating system version 5.1 (see Fig. 5).

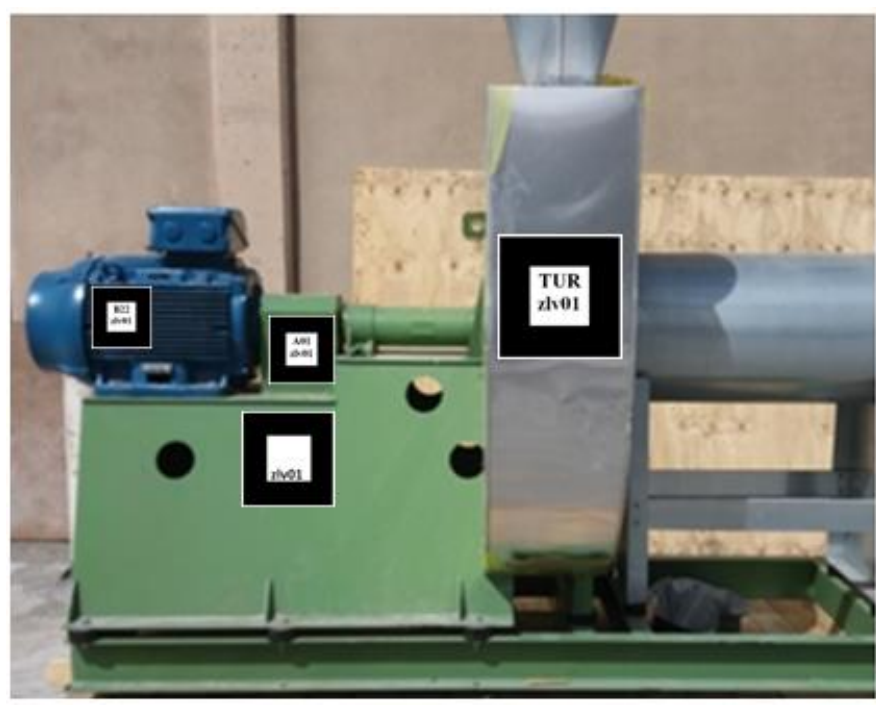

Fig. 5 Example of equipment Draft fan

Fig. 6 and Fig. 7 shows examples on our A.R.P.M. system, the augmented view that maintenance technician can see through a Smartphone during an inspection. Fig. 8 represents the interface of A.R.P.M system application. 


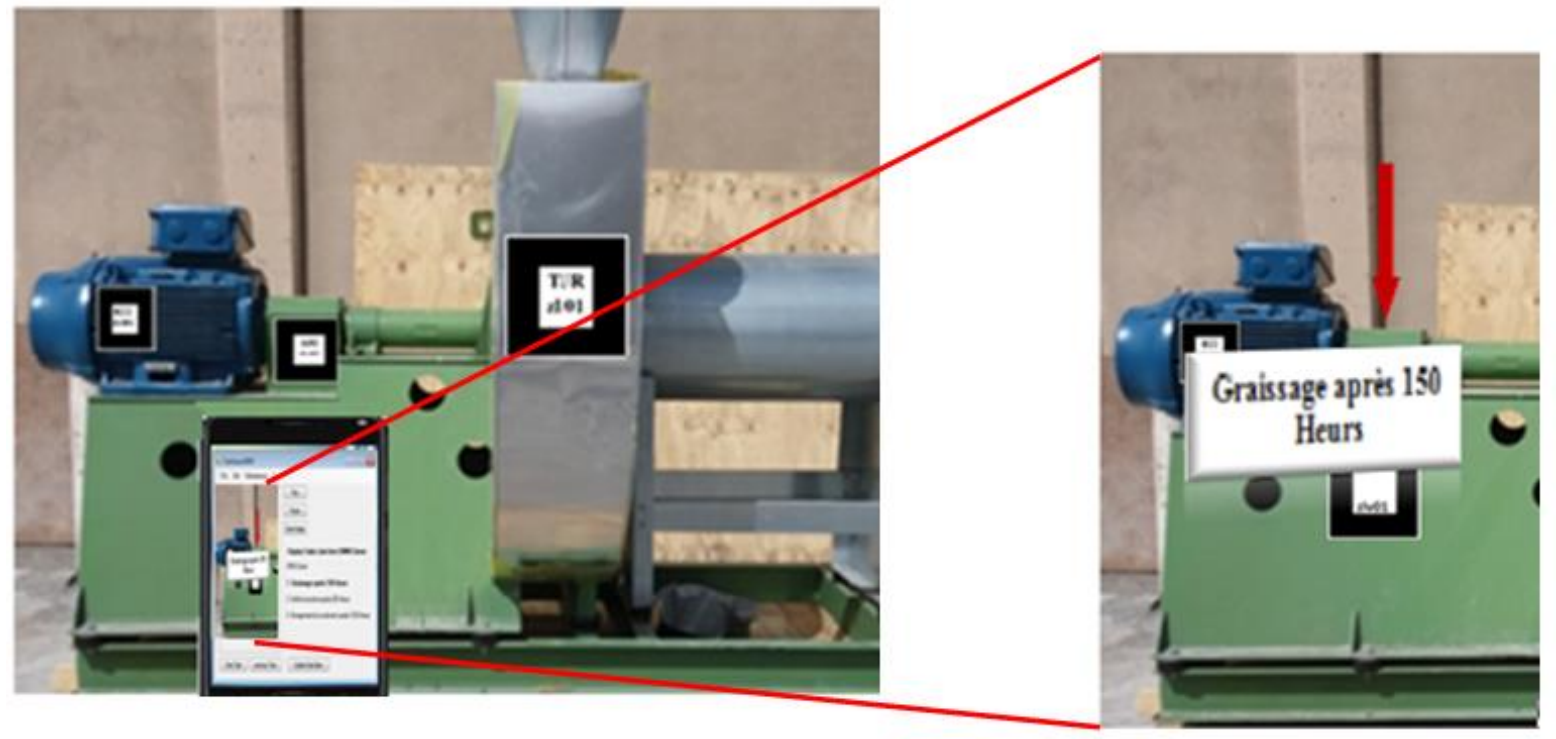

Fig.6 Bearing lubrication after 150 hours

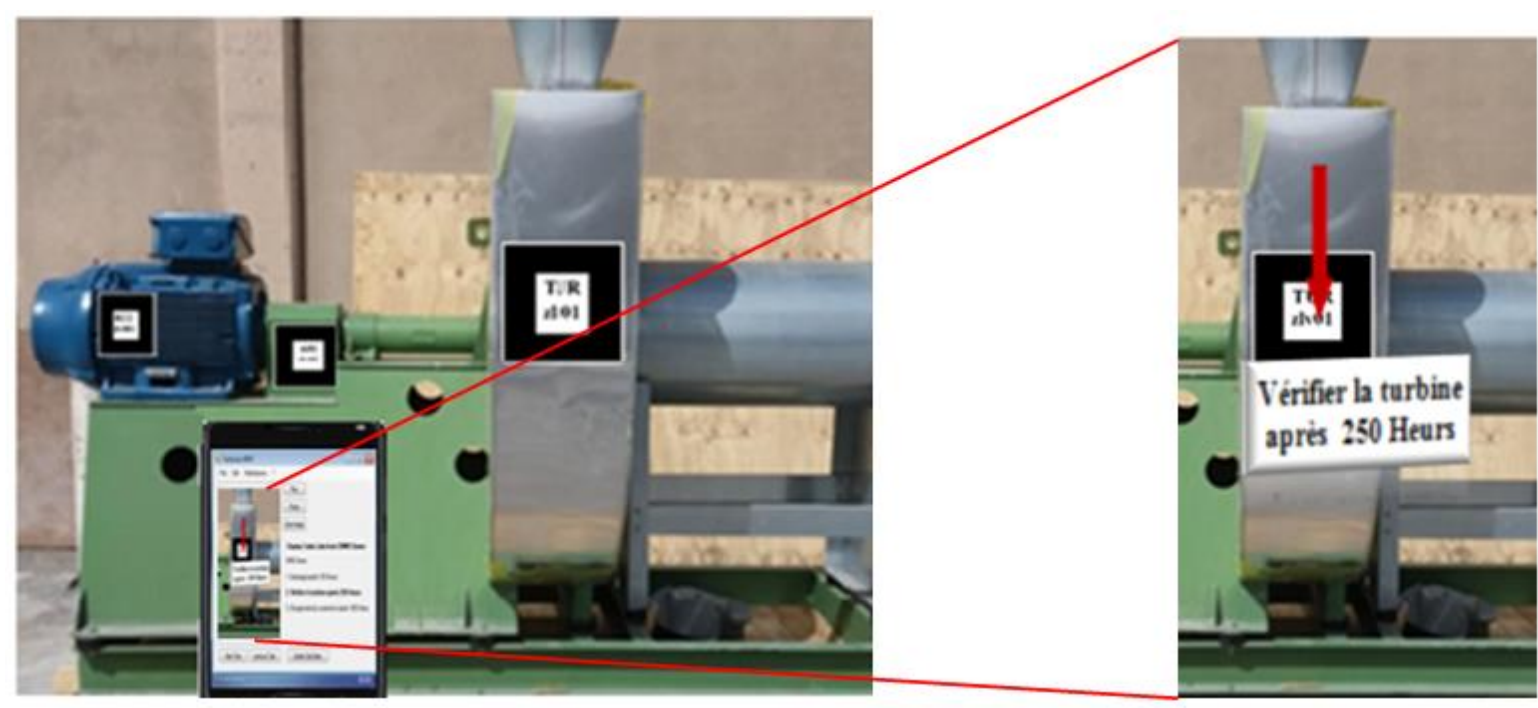

Fig.7 Verification of the turbine after 250 hours

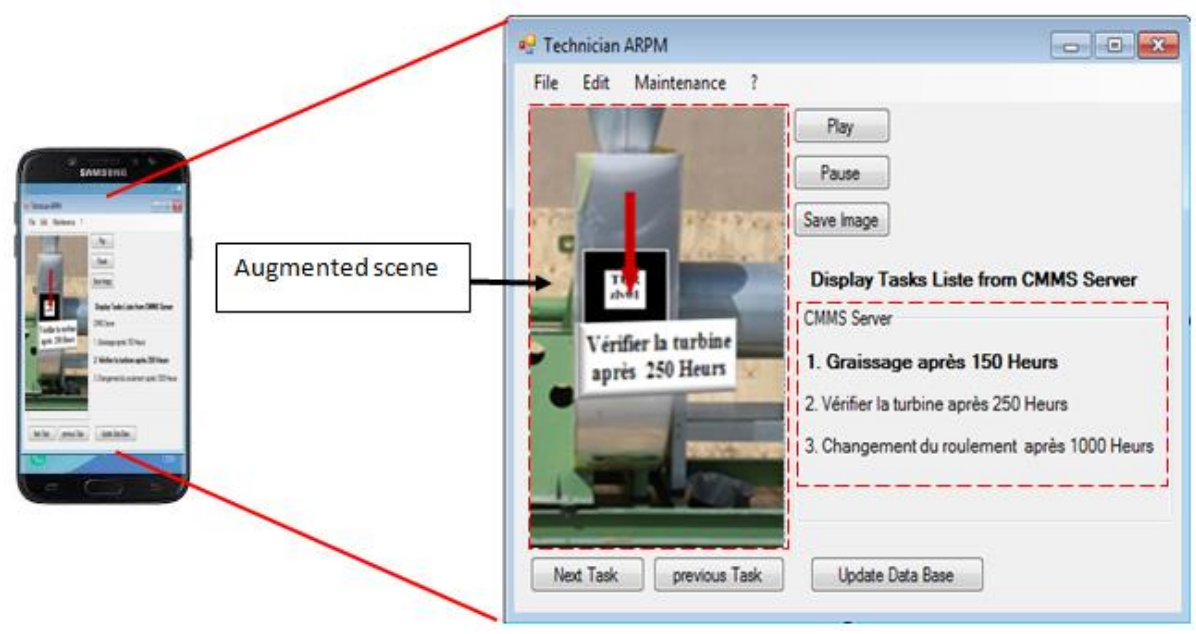

Fig.8 Interface of ARPM application 


\section{CONCLUSION}

In this work, we presented A.R.P.M. system which allows the inspector to see, on-site and in real time, all the information related to the preventive maintenance operations for each equipment. We have developed our system on a mobile device (Android Smartphone), and we tested it with the technicians of the Cement factory on the draft fan of the filtration workshop. In addition, we plan to integrate a remote module for the system in order to support e-maintenance assistance.

\section{ACKNOWLEDGMENT}

The authors wish to thank the service group OSM (Office of Study and Methods) of the cement company Tébessa (SCT) maintenance specialist, HALFAYA Abedelmalek Head of Department (CMR) Control Measure and Regulation for his help on the various operations of preventive maintenance in the oven workshop.

\section{REFERENCES}

[1] Norme, AFNOR. Statistique et Qualité , introduction à la fiabilité. Novembre 1977. X NF, 06-501.

[2] SCT. Fiches historiques de mise en marche du four et processus de fabrication du ciment.Elma-Labiod, Tebessa. 1988-1995.

[3] MONCHY, François. La fonction maintenance: Formation à la gestion de la maintenance industrielle. Masson, 1987.

[4] CAUDELL, Thomas P.; MIZELL, David W. Augmented reality: An application of heads-up display technology to manual manufacturing processes. In: System Sciences, 1992. Proceedings of the TwentyFifth Hawaii International Conference on. IEEE, 1992. p. 659-669.

[5] MARSOT, J.; GARDEUX, F.; GOVAERE, V. Réalité augmentée et prévention des risques: apports et limites. Revue of Hygiène et sécurité du travail, 2009, 15-23.

[6] OPTRONIQUE, Thomson-CSF; GUYANCOURT, France; SA Tecnatom. STARMATE: Using Augmented Reality technology for computer guided maintenance of complex mechanical elements.

[7] RIESS, Patrick. AR-on-demand: A practicable solution for augmented reality on low-end handheld devices. In: Workshop Virtuelle und Erweiterte Realitat der GI-Fachgruppe VR/AR, 2006. 2006. p. 119-130.

[8] PLATONOV, Juri, et al. A mobile markerless AR system for maintenance and repair. In: Mixed and Augmented Reality, 2006 ISMAR 2006. IEEE/ACM International Symposium on. IEEE, 2006. p. $105-108$.

[9] HENDERSON, Steven; FEINER, Steven. Exploring the benefits of augmented reality documentation for maintenance and repair. IEEE transactions on visualization and computer graphics, 2011, 17.10: $1355-1368$.

[10] DIDIER, Jean-Yves. Contributions à la dextérité d'un système de réalité augmentée mobile appliqué à la maintenance industrielle. 2005. PhD Thesis. Université d'Evry-Val d'Essonne.

[11] BOTTECCHIA, Sébastien; CIEUTAT, Jean-Marc; JESSEL, JeanPierre. TAC: augmented reality system for collaborative teleassistance in the field of maintenance through internet. In Proceedings of the 1st Augmented Human International Conference. ACM, 2010. p. 14.

[12] ZENATI-HENDA, Nadia. Contribution à la conception et à la réalisation d'un système de réalité augmentée pour la maintenance. 2008. PhD Thesis. Université de Franche-Comté.

[13] ZENATI-HENDA, Nadia, BELLARBI, Abdelkader, BENBELKACEM, Samir, et al. Augmented reality system based on hand gestures for remote maintenance. In : Multimedia Computing and Systems (ICMCS), 2014 International Conference on. IEEE, 2014. p. 5-8.
[14] Benbelkacem, S., Zenati-Henda, N., Belhocine, M., Bellarbi, A., Tadjine, M., \& Malek, S. (2010, November). Augmented reality platform for solar systems maintenance assistance. In Proceedings of International Symposium on Environment Friendly Energies in Electrical Applications. Ghardaia, Algeria.

[15] BENBELKACEM, Samir, BELHOCINE, Mahmoud, BELLARBI, Abdelkader, et al. Augmented reality for photovoltaic pumping systems maintenance tasks. Renewable energy, 2013, vol. 55, p. 428437.

[16] ZENATI, Nadia, HAMIDIA, Mahfoud, BELLARBI, Abdelkader, et al. E-maintenance for photovoltaic power system in Algeria. In : Industrial Technology (ICIT), 2015 IEEE International Conference on. IEEE, 2015. p. 2594-2599. 